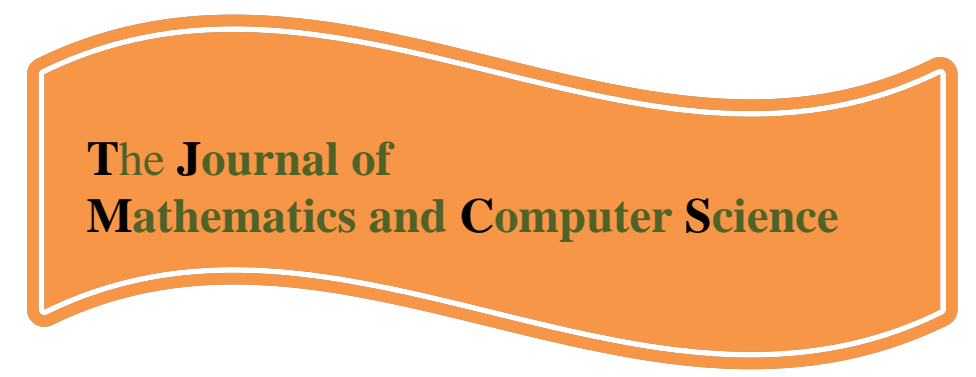

Available online at

http://www.TJMCS.com

The Journal of Mathematics and Computer Science Vol .1 No.4 (2010) 258-272

\title{
Comparing Fuzzy Charts with Probability Charts and Using Them in a Textile Company
}

\author{
Hamid Reza Feili ${ }^{1 *}$, Pooyan Fekraty ${ }^{2}$ \\ Hrfeili@gmail.com \\ pooyan_fekraty@yahoo.com
}

Received: August 2010, Revised: October 2010

Online Publication: December 2010

\begin{abstract}
In this article it has been tried to show that fuzzy theory performs better than probability theory in monitoring the product quality. A method that uses statistical techniques to monitor and control product quality is called statistical process control (SPC), where control charts are test tools frequently used for monitoring the manufacturing process. In this study, statistical quality control and the fuzzy set theory are aimed to combine. As known, fuzzy sets and fuzzy logic are powerful mathematical tools for modeling uncertain systems in industry, nature and humanity; and facilitators for common-sense reasoning in decision making in the absence of complete and precise information. In this basis for a textile firm for monitoring the yarn quality, control charts according to fuzzy theory by considering the quality in terms of grades of conformance as opposed to absolute conformance and nonconformance. And then with the same data for a textile factory, the control chart based on probability theory is constructed. The results of control charts based on two different approaches are compared. It's seen that fuzzy theory performs better than probability theory in monitoring the product quality.
\end{abstract}

Keywords: Quality Control Charts, Fuzzy Set Theory, Fuzzy Control Charts, Statistical Process Control, Textile

\footnotetext{
1*. Assistant Professor, Industrial Engineering, Alzahra University

${ }^{2}$. B.S, Industrial Engineering, K.N.T.University
} 


\section{Introduction}

Successful businesses inevitably place great emphasis on managing quality control - carefully planned steps taken to ensure that the products and services offered to their customers are consistent and reliable and truly meet their customers' needs. Many quality characteristics (Q.Ch.) are expressed in terms of original or its derived measurement units, like weight, length, pressure, etc. for which they are called continuous or variable. As normality is a usual assumption of control charts of continuous Q.Ch.s and independency of mean and variance is a basic assumption of normal distribution, a separate control chart is prepared for monitoring the process average. As the literature of a Shewhartian control chart and fuzzy theory is quite famous and available in different related texts and articles we will generally discuss them in the following lines.

\section{Quality Control}

Quality control is a process employed to ensure a certain level of quality in a product or service. It may include whatever actions a business deems necessary to provide for the control and verification of certain characteristics of a product or service. The basic goal of quality control is to ensure that the products, services, or processes provided meet specific requirements and are dependable, satisfactory, and fiscally sound.

One of the primary tools used in the statistical control of a process is the control chart. Created by Walter Shewhart in 1924, the Shewhart control chart gives a crisp picture of the state of a process by plotting the data produced by a process on a chart bound by upper and lower specification limits. The main function of a control chart is to

Monitor a process in order to identify whether or not the process is in control. "In control" conditions mean that a process is producing parts that are close to the target value with little variation. "Out of control" conditions mean that some type of assignable cause has occurred, and the process is, therefore, yielding products at either an unacceptable distance from the target value, with an unacceptable amount of variation, or both. The control chart consists of three lines: an upper control limit (UCL), a lower control limit (LCL), and a center line (CL) (Refer to Fig 1). The upper and lower control limits are the maximum and minimum values for a process characteristic to be considered in control while the center line is the mean value for the process. For Shewhart charts, 3sigma control limits are used. Three sigma ( $3 \sigma$ ) control limits establish bounds on the data that extend above and below the mean of the process by 3 times the standard deviation of the process statistic being plotted. Data to be plotted on control charts are obtained directly from the process. Data points falling outside the set limits indicate a possible out of control condition in the process .

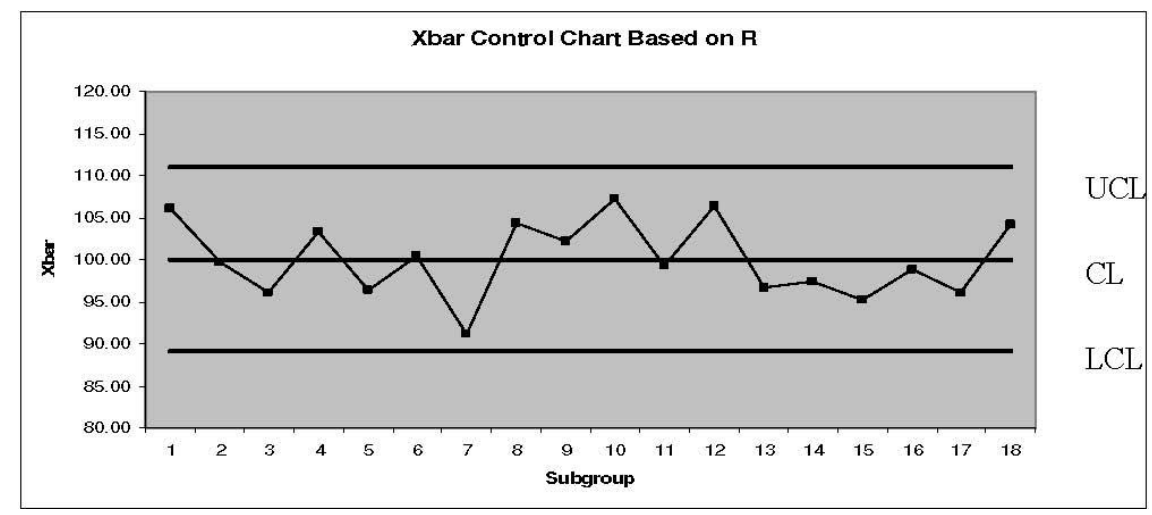

Fig1. X Control Chart Using R

The information plotted on control charts consists of either variable or attribute data. Variable data 
represent measurable characteristics. Examples of variable data are dimensions such as diameters, volumes, or lengths. Attribute data are data that refer to either a pass or a fail situation. In other words, if a product passes inspection, it is considered a pass, and thus, it conforms to the standards outlined for the product. If a product fails, it is considered nonconforming to the standards outlined for the product.

\section{Fuzzy Logic and Fuzzy Set Theory}

Fuzzy logic is a form of multi-valued logic derived from fuzzy set theory to deal with reasoning that is approximate rather than accurate. In contrast with "crisp logic", where binary sets have binary logic, fuzzy logic variables may have a truth value that ranges between 0 and 1 and is not constrained to the two truth values of classic propositional logic. Furthermore, when linguistic variables are used, these degrees may be managed by specific functions. Fuzzy logic emerged as a consequence of the 1965 proposal of fuzzy set theory by Lotfi Zadeh. Though fuzzy logic has been applied to many fields, from control theory to artificial intelligence, it still remains controversial among most statisticians, who prefer Bayesian logic, and some control engineers, who prefer traditional two-valued logic.

Fuzzy logic and probabilistic logic are mathematically similar - both have truth values ranging between 0 and 1 - but conceptually distinct, due to different interpretations. Fuzzy logic corresponds to "degrees of truth", while probabilistic logic corresponds to "probability, likelihood"; as these differ, fuzzy logic and probabilistic logic yield different models of the same real-world situations. Both degrees of truth and probabilities range between 0 and 1 and hence may seem similar at first. It is essential to realize that fuzzy logic uses truth degrees as a mathematical model of the vagueness phenomenon while probability is a mathematical model of ignorance. The same could be achieved using probabilistic methods. A basic application might characterize sub ranges of a continuous variable. For instance, a temperature measurement for anti-lock brakes might have several separate membership functions defining particular temperature ranges needed to control the brakes properly. Each function maps the same temperature value to a truth value in the 0 to 1 range. These truth values can then be used to determine how the brakes should be controlled.

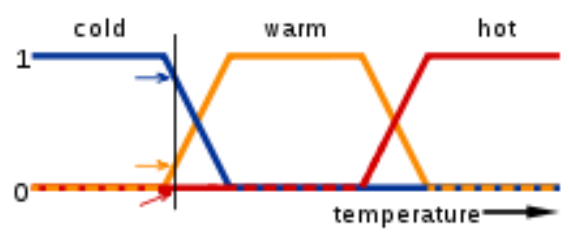

Fig2. Temperature scale

In this image, the meaning of the expressions cold, warm, and hot is represented by functions mapping a temperature scale. A point on that scale has three "truth values"-one for each of the three functions. The vertical line in the image represents a particular temperature that the three arrows (truth values) gauge. Since the red arrow points to zero, this temperature may be interpreted as "not hot". The orange arrow (pointing at 0.2) may describe it as "slightly warm" and the blue arrow (pointing at 0.8) "fairly cold".

Fuzzy sets are sets whose elements have degrees of membership. In classical set theory the membership of elements in a set is assessed in binary terms according to a bivalent condition - an element either belongs or does not belong to the set. By contrast, fuzzy set theory permits the gradual assessment of the membership of elements in a set; this is described with the aid of a membership function valued in the real unit interval $[0,1]$. Fuzzy sets generalize classical sets, since the indicator 
functions of classical sets are special cases of the membership functions of fuzzy sets, if the latter only take values 0 or 1 . Classical bivalent sets are in fuzzy set theory usually called crisp sets. The fuzzy set theory can be used in a wide range of domains in which information is incomplete or imprecise.

\section{Constructing Quality Control Charts by using Probability and Fuzzy Approaches}

There are many situations in which the simultaneous control of two or more related quality characteristics is necessary. For example, suppose that a bearing has both an inner diameter(x1) and an outer diameter (x2) that together determine the usefulness of the part. Controlling these two quality characteristics independently can be very misleading. And the distortion in the control procedure increases as the number of quality characteristics increases (Montgomery 1991). Like that quality control problems in which several related variables are interest are sometimes called multivariate quality control problems. Different procedures are proposed to monitor multinomial processes when products are classified into mutually exclusive categories. Marcucci proposed two procedures using Shewart type control charts. The first type is used when quality proportions are designed to be specific values, where any change in these proportions must be detected by the monitoring procedure. The second type allows for one-sided monitoring of quality proportions and is designed to detect only an increase in all but one quality proportions. When specific values of process proportions are not known, the Pearson goodnessof-fit statistic is not applicable. An appropriate statistical procedure that is a test of homogeneity of proportions between the base period $(0)$ and each monitoring period (i) is defined as follows:

$$
Z_{i}^{2}=\sum_{k=i, 0} \sum_{j=1}^{t} \frac{n_{k}\left(\frac{X_{k j}}{n_{k}}-\frac{X_{i j}+X_{0 j}}{n_{i}+n_{0}}\right)}{\frac{X_{i j}+X_{0 j}}{n_{i}+n_{0}}}=n_{i} n_{0} \sum_{j=1}^{t} \frac{\left(p_{i j}-p_{0 j}\right)}{X_{i j}+X_{0 j}}
$$

where $\mathrm{k}=\{0,1\}, \mathrm{pkj}=\mathrm{Xkj} / \mathrm{nk}, \mathrm{j}=1,2,3, \ldots, \mathrm{t}$ are the sample proportions and $\mathrm{n} i$ is the sample size. Raz andWang proposed an alternative approach based on fuzzy theory. Fuzzy sets are assigned to each linguistic term, and then using rules of fuzzy arithmetic they are combined for each sample. The result is a single fuzzy set. A measure of centrality of this aggregate fuzzy set is then plotted on a Shewart-type control chart. In order to retain the standard format of control charts and to facilitate the plotting of observations on the chart, it is necessary to convert the fuzzy sets associated with the linguistic values into scalars, which will be referred to as representative values (Wang and Raz 1990). This may be done in a number of ways, as long as the result is intuitively representative of the range of the base variable included in the fuzzy set. Four ways, which are similar in descriptive statistics, are presented.

1. Fuzzy mode, fmode: The fuzzy mode of a fuzzy set $\mathrm{F}$ is the value of the base variable where the membership function equals 1 . This is stated.

$$
\mathrm{f}_{\text {mod }}=\left\{\mathrm{x} \mid \mu_{\mathrm{F}}(\mathrm{x})=1\right\}, \quad \forall \mathrm{x} \in \mathrm{F}
$$

2. $\alpha$-Level fuzzy midrange, $\operatorname{fmr}(\alpha)$ : This is defined as the midpoint of the ends of the $\alpha$ level cut. An $\alpha$ level cut denoted by $\mathrm{A} \alpha$ is a non fuzzy set which comprises all elements whose membership is greater than or equal to $\alpha$. If a $\alpha$ and $\mathrm{b} \alpha$, are the end of points of $\mathrm{A} \alpha$ then.

$$
\mathrm{f}_{\mathrm{mr}}(\alpha)=\frac{1}{2}\left(\mathrm{a}_{\alpha}+\mathrm{b}_{\alpha}\right)
$$


3. Fuzzy median, fmed : This is the point which partitions the curve under the membership function of a fuzzy set into equal regions satisfying the following equations. where $a$ and $b$ are the end points in the base variable of fuzzy set $F$ such that $a<b$.

$$
\int_{\mathrm{a}}^{\mathrm{f}_{\text {med }}} \mu_{\mathrm{F}}(\mathrm{x}) \mathrm{dx}=\int_{\mathrm{f}_{\text {med }}}^{\mathrm{b}} \mu_{\mathrm{F}}(\mathrm{x}) \mathrm{dx}=\frac{1}{2} \int_{\mathrm{a}}^{\mathrm{b}} \mu_{\mathrm{F}}(\mathrm{x}) \mathrm{dx}
$$

4. Fuzzy average, favg: based on Zadeh, the fuzzy average is (Wang and Raz 1990).

$$
\mathrm{f}_{\mathrm{avg}}=\operatorname{Av}(\mathrm{x}: \mathrm{F})=\frac{\int_{\mathrm{x}=0}^{1} \mathrm{x} \mu_{\mathrm{F}}(\mathrm{x}) \mathrm{dx}}{\int_{\mathrm{x}=0}^{1} \mu_{\mathrm{F}}(\mathrm{x}) \mathrm{dx}}
$$

It should be pointed out that there is no theoretical basis supporting any one specifically. The selection among them should be mainly based on the ease of computation or the user's preference (Gülbay and Kahraman 2007). After transforming the each fuzzy subset into their representative values, Wang and Raz developed two approaches called the membership approach and the fuzzy probabilistic approach. In the membership approach, membership control limits are based on membership functions. For m samples of size n,Wang and Raz described the centerline (CL) (Eq. 6) as the grand average of means of the samples initially available and calculated the mean deviation for a given fuzzy set $A(\delta(A)$ ) (Eq. 8) by using the sum of the left mean deviation $(\delta \mathrm{l})$, and the right mean deviation $(\delta \mathrm{r})$.

$$
\mathrm{CL}=\overline{\mathrm{M}}_{\mathrm{j}}=\frac{\sum_{\mathrm{j}=1}^{\mathrm{m}} \mathrm{M}_{\mathrm{j}}}{\mathrm{m}}
$$

where $\mathrm{Mj}$ (Eq. 7) is the sample mean of the jth sample, $M j$ is the average sample mean, and $\mathrm{m}$ is the number of sample initially available:

$$
M_{j}=\frac{\sum_{j=1}^{m} k_{i j} r_{i}}{n_{j}}, i=1,2,3 \ldots, t
$$

where kij is the number of products categorized with the linguistic term L in the sample $\mathrm{j}$; ri is the fuzzy representative value of the linguistic term $i$ and $n j$ is the size of sample $j$.

$$
\begin{aligned}
& \delta_{\mathrm{l}}=\int_{\alpha=0}^{1}\left[\mathrm{x}_{\mathrm{m}}-\mathrm{x}_{\mathrm{l}}(\alpha)\right] \mathrm{d} \alpha \text { and } \delta_{\mathrm{r}}=\int_{\alpha=0}^{1}\left[\mathrm{x}_{\mathrm{r}}-\mathrm{x}_{\mathrm{m}}(\alpha)\right] \mathrm{d} \alpha \\
& \delta(\mathrm{A})=\delta_{\mathrm{l}}(\mathrm{A})+\delta_{\mathrm{r}}(\mathrm{A})=\int_{\alpha=0}^{1}\left[\mathrm{x}_{\mathrm{r}}(\alpha)-\mathrm{x}_{\mathrm{l}}(\alpha)\right] \mathrm{d} \alpha
\end{aligned}
$$

where $\alpha$ is the value of membership. The control limits (Eq. 9) are located below and above the central line at distances expressed as multiples of the mean deviation. Because the representative value of each sample will be range $[0,1]$.

$$
\begin{aligned}
& \text { Membership } L C L=\operatorname{Max}\{0,[\mathrm{CL}-\mathrm{k} \delta(\mathrm{GMF})]\} \\
& \text { Membership } U C L=\operatorname{Min}\{0,[\mathrm{CL}+\mathrm{k} \delta(\mathrm{GMF})]\}
\end{aligned}
$$


In the fuzzy probabilistic approach, fuzzy subsets $\mathrm{Fi}$ associated with the linguistic terms $\mathrm{Li}$ are transformed into their respective values ri with one of the transformation methods. The sample mean $\mathrm{Mj}$ (Eq. 10) is calculated as the average of the sample linguistic representative values, ri. For each sample j, the standard deviation SDj (Eq. 11) is calculated as the standard deviation of the representative values of the observations in the sample:

$$
\begin{aligned}
& \mathrm{M}_{\mathrm{j}}=\sum_{\mathrm{i}=1}^{\mathrm{t}} \mathrm{r}_{\mathrm{i}} \mathrm{k}_{\mathrm{ij}} \\
& \mathrm{SD}_{\mathrm{j}}=\sqrt{\frac{1}{\mathrm{n}-1} \sum_{\mathrm{i}=1}^{\mathrm{t}} \mathrm{k}_{\mathrm{ij}}\left(\mathrm{r}_{\mathrm{i}}-\mathrm{M}_{\mathrm{j}}\right)^{2}}
\end{aligned}
$$

where $t$ is the number of linguistic term in the term set, ri is the representative value of the fuzzy set associated with the linguistic term $\mathrm{Li}$ and $\mathrm{Mj}$ is the mean of the representative values in the sample $\mathrm{j}$. The mean of the representative of them samples, MSD, is then,

$$
\mathrm{MSD}=\frac{1}{\mathrm{~m}} \sum_{\mathrm{j}=1}^{\mathrm{m}} \mathrm{SD}_{\mathrm{j}}
$$

The centerline calculated as the grand mean of the sample means $\mathrm{Mj}$ as follows:

$$
\mathrm{CL}=\frac{\sum_{\mathrm{j}=1}^{\mathrm{m}} \mathrm{M}_{\mathrm{j}}}{\mathrm{m}}=\frac{\sum_{\mathrm{j}=1}^{\mathrm{m}} \sum_{\mathrm{i}=1}^{\mathrm{t}} \mathrm{r}_{\mathrm{i}} \mathrm{k}_{\mathrm{ij}}}{\mathrm{mn}}
$$

Because the points plotted on the charts are sample means of representative values, they should lie within the range $[0,1]$. Consequently, assuming the sampling distribution is approximately normal or the sample size $\mathrm{n}$ is relatively large $(>25)$, by applying the standard formula from variables control charts control limits are derived as (Gülbay et al. 2004):

$$
\begin{aligned}
& L C L=\operatorname{Max}\left\{0,\left(C L-\mathrm{A}_{3} \mathrm{MSD}\right)\right\} \\
& U C L=\operatorname{Min}\left\{1,\left(\mathrm{CL}+\mathrm{A}_{3} \mathrm{MSD}\right)\right\}
\end{aligned}
$$

\section{An Application in a Textile Company}

he data are taken one of the biggest textile company in Iran. This company produces cotton yarn called Ne30 and following data shows the quality of Ne30 cotton yarn. The company classifies the yarn quality into four categorizes; standard, 1th preferences, 2th preferences and useless. Data 30 samples of different sizes taken every day is shown in Table 1.

Table 1 . Data for the quality of yarn in a cotton industry

\begin{tabular}{|c|c|c|c|c|c|}
\hline Sample & Standard & $\begin{array}{c}1 \text { th } \\
\text { Preference }\end{array}$ & $\begin{array}{c}2 \text { th } \\
\text { Preference }\end{array}$ & Useless & Size \\
\hline 1 & 5 & 9 & 6 & 4 & 24 \\
\hline 2 & 9 & 4 & 6 & 5 & 24 \\
\hline
\end{tabular}


Hamid Reza Feili, Pooyan Fekraty / TJMCS Vol .1 No.4 (2010) 257-272

\begin{tabular}{|c|c|c|c|c|c|}
\hline 3 & 11 & 5 & 5 & 3 & 24 \\
\hline 4 & 5 & 4 & 13 & 4 & 24 \\
\hline 5 & 7 & 6 & 2 & 9 & 24 \\
\hline 6 & 7 & 5 & 7 & 5 & 24 \\
\hline 7 & 11 & 7 & 4 & 2 & 24 \\
\hline 8 & 1 & 11 & 2 & 10 & 24 \\
\hline 9 & 5 & 6 & 9 & 4 & 24 \\
\hline 10 & 6 & 5 & 4 & 9 & 24 \\
\hline 11 & 9 & 4 & 5 & 6 & 24 \\
\hline 12 & 5 & 11 & 1 & 7 & 24 \\
\hline 13 & 8 & 9 & 4 & 3 & 24 \\
\hline 14 & 4 & 2 & 5 & 13 & 24 \\
\hline 15 & 5 & 11 & 3 & 5 & 24 \\
\hline 16 & 2 & 10 & 4 & 4 & 20 \\
\hline 17 & 4 & 9 & 6 & 5 & 24 \\
\hline 18 & 5 & 12 & 3 & 4 & 24 \\
\hline 19 & 6 & 12 & 3 & 3 & 24 \\
\hline 20 & 3 & 11 & 2 & 8 & 24 \\
\hline 21 & 4 & 10 & 2 & 6 & 24 \\
\hline 22 & 6 & 13 & 1 & 4 & 24 \\
\hline 23 & 3 & 9 & 0 & 4 & 16 \\
\hline 24 & 7 & 6 & 6 & 5 & 24 \\
\hline 25 & 3 & 12 & 4 & 5 & 24 \\
\hline 26 & 5 & 10 & 6 & 3 & 24 \\
\hline 27 & 4 & 11 & 3 & 6 & 24 \\
\hline 28 & 4 & 8 & 4 & 0 & 16 \\
\hline 29 & 8 & 9 & 3 & 4 & 24 \\
\hline 30 & 2 & 4 & 9 & 9 & 24 \\
\hline
\end{tabular}

The textile example corresponds to the second type of Marcucci procedures. Suppose that the process is in control in the period corresponding to sample 8. We can estimate the sample proportions for the base period as follows:

$$
\mathrm{p}_{01}=\frac{11}{24}=0.46, \mathrm{p}_{02}=0.29, \mathrm{p}_{03}=0.17, \mathrm{p}_{04}=0.08
$$

The statistics to be plotted in the control chart for each sample is calculated according to the Eq. 1. The obtained results for 30 samples are shown in Table 2.

Table 2. statistics to be plotted in the quality control chart for 30 samples

\begin{tabular}{|c|c|c|c|c|c|c|c|c|c|c|c|c|c|c|c|}
\hline Sample & 1 & 2 & 3 & 4 & 5 & 6 & 7 & 8 & 9 & 10 & 11 & 12 & 13 & 14 & 15 \\
\hline$Z_{i}^{2}$ & 3.114 & 3.340 & 0.461 & 8.754 & 6.763 & 3.348 & 6.006 & 0.003 & 14.561 & 3.181 & 9.901 & 4.852 & 2.348 & 15.342 & 11.207 \\
\hline Sample & 16 & 17 & 18 & 19 & 20 & 21 & 22 & 23 & 24 & 25 & 26 & 27 & 28 & 29 & 30 \\
\hline$Z_{i}^{2}$ & 9.239 & 5.312 & 3.541 & 2.233 & 9.954 & 11.616 & 7.566 & 8.434 & 2.695 & 9.534 & 5.465 & 6.584 & 3.805 & 0.981 & 10.057 \\
\hline
\end{tabular}


The resulting generalized p chart is illustrated in Fig. 3. The upper control limit is taken to be the 95th percentile of the $x^{2}(3)$ distribution which is 7,815. In a generalized p-chart the upper control limit does not change for all multinomial processes that have the same number of categories.

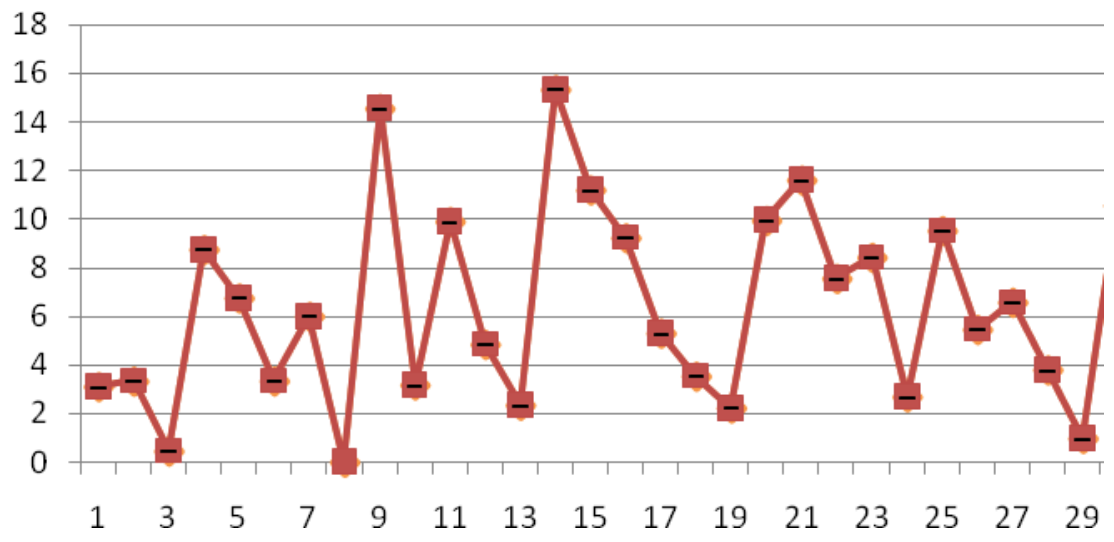

Fig3. Generalized p chart for yarn process

\section{Set 1}

$$
\begin{gathered}
\mu_{\mathrm{s}}=\left\{\begin{array}{ll}
0, & \mathrm{x} \leq 0 \\
-2 \mathrm{x}+1, & 0 \leq \mathrm{x} \leq 0.5 \\
0, & \mathrm{x} \geq 0.5
\end{array} \quad \mu_{1 \mathrm{p}}= \begin{cases}0, & \mathrm{x} \leq 0 \\
4 \mathrm{x}, & 0 \leq \mathrm{x} \leq 0.25 \\
-2 \mathrm{x}+\frac{3}{2}, & 0.25 \leq \mathrm{x} \leq 0.75 \\
0, & 0.75 \leq \mathrm{x}\end{cases} \right. \\
\mu_{2 \mathrm{p}}=\left\{\begin{array}{ll}
0, & \mathrm{x} \leq 0.25 \\
4 \mathrm{x}, & 0.25 \leq \mathrm{x} \leq 0.5 \\
-2 \mathrm{x}+2, & 0.5 \leq \mathrm{x} \leq 1 \\
0, & 1 \leq \mathrm{x}
\end{array} \mu_{\mathrm{u}}= \begin{cases}0, & \mathrm{x} \leq 0.5 \\
2 \mathrm{x}-1, & 0.5 \leq \mathrm{x} \leq 1 \\
0, & 1 \leq \mathrm{x}\end{cases} \right.
\end{gathered}
$$

Table 3. Membership functions for yarn process (for set 1)

Set 2

$$
\begin{aligned}
& \mu_{\mathrm{s}}=\left\{\begin{array}{ll}
0, & \mathrm{x} \leq 0 \\
-4 \mathrm{x}+1, & 0 \leq \mathrm{x} \leq 0.25 \\
0, & \mathrm{x} \geq 0.25
\end{array} \mu_{1 \mathrm{p}}= \begin{cases}0, & \mathrm{x} \leq 0 \\
4 \mathrm{x}, & 0 \leq \mathrm{x} \leq 0.25 \\
-4 \mathrm{x}+2, & 0.25 \leq \mathrm{x} \leq 0.5 \\
0, & 0.5 \leq \mathrm{x}\end{cases} \right. \\
& \mu_{2 \mathrm{p}}=\left\{\begin{array}{ll}
0, & \mathrm{x} \leq 0.25 \\
4 \mathrm{x}-1, & 0.25 \leq \mathrm{x} \leq 0.5 \\
-4 \mathrm{x}+3, & 0.5 \leq \mathrm{x} \leq 0.75 \\
0, & 0.75 \leq \mathrm{x}
\end{array} \mu_{\mathrm{u}}= \begin{cases}0, & \mathrm{x} \leq 0.5 \\
2 \mathrm{x}-1, & 0.5 \leq \mathrm{x} \leq 1 \\
0, & 1 \leq \mathrm{x}\end{cases} \right.
\end{aligned}
$$


Table 4. Membership functions for the yarn process (for Set 2)

Table 5. Representative values of linguistic terms for two sets

\begin{tabular}{|l|c|c|c|c|}
\hline \multirow{2}{*}{} & \multicolumn{2}{|c|}{ Fuzzy mode } & \multicolumn{2}{c|}{ Fuzzy median } \\
\cline { 2 - 5 } & Set 1 & Set 2 & Set 1 & Set 2 \\
\hline Standard & 0 & 0 & 0.143 & 0.073 \\
\hline 1th Preference & 0.25 & 0.25 & 0.317 & 0.25 \\
\hline 2th Preference & 0.5 & 0.5 & 0.57 & 0.5 \\
\hline Useless & 1 & 1 & 0.854 & 0.75 \\
\hline
\end{tabular}

\section{Wang and Raz Approach}

In this study Standard (S), 1th Preferences (1P), 2th Preferences (2P), Useless (U) are determined as the term set and then membership functions are expressed for each term. Two sets of membership functions with different shapes are used and shown in Tables 3 and 4 . In our study fuzzy mode and fuzzy median are used as a transformation method. Fuzzy mode and fuzzy median for two sets of memberships are calculated with the help of Eqs. 2 and 4. Results obtained are shown in Table 5.

\section{Probabilistic Approach}

As can be seen from Table 5, the value of fuzzy modes for two sets of membership functions is the same so the representative values of fuzzy subsets for two sets are same. But the values of fuzzy median for two sets of membership are different so the representative values of fuzzy subsets are different. Because of this reason, control charts produced by different sets are the same when the fuzzy mode is used and are different when the fuzzy median is used. For probabilistic approach, mean and standard deviation of each sample are calculated according to Eqs. 10 and 11. Mean of standard deviation (MSD) is calculated from Eq. 12 and then upper and lower control limits are obtained from Eq. 13. The results obtained for 30 samples are shown in Table 6. The constructed fuzzy probabilistic control chart using fuzzy mode can be seen in Fig. 4. The upper and lower control limits for sample 16, 22, 23 and 28 are different from other samples'. Because their sample sizes are different from others so they have different upper and lower control limits. Sample 14 is out of the control. The same calculation steps are repeated again for constructing fuzzy probabilistic chart by using fuzzy median as a representative of fuzzy subsets. As can be mentioned before, the representative values of each fuzzy subset for two sets are different when fuzzy median method is used so constructed control charts for two sets are different. But in this study only control charts for set 2 are shown. Table 7 is related with set 1 and shows mean and standard deviation of each sample and lower and upper control limits of each sample. And Table 8 is related with set 2 and shows mentioned parameters. The fuzzy probabilistic control chart for set 2 is shown in Fig. 5.

Table 6. Results of applying fuzzy probabilistic approach (fuzzy mode)

\begin{tabular}{|c|c|c|c|c|c|c|c|c|c|}
\hline Sample & $\mathrm{Mj}$ & $\mathrm{SDj}$ & $\mathrm{LCL}$ & $\mathrm{UCL}$ & Samples & $\mathrm{Mj}$ & $\mathrm{SDj}$ & $\mathrm{LCL}$ & UCL \\
\hline 1 & 0.376 & 0.337 & 0.212 & 0.619 & 16 & 0.481 & 0.321 & 0.192 & 0.639 \\
\hline 2 & 0.354 & 0.392 & 0.212 & 0.619 & 17 & 0.439 & 0.343 & 0.212 & 0.619 \\
\hline 3 & 0.237 & 0.298 & 0.212 & 0.619 & 18 & 0.364 & 0.324 & 0.212 & 0.619 \\
\hline 4 & 0.464 & 0.309 & 0.212 & 0.619 & 19 & 0.298 & 0.309 & 0.212 & 0.619 \\
\hline
\end{tabular}


Hamid Reza Feili, Pooyan Fekraty / TJMCS Vol .1 No.4 (2010) 257-272

\begin{tabular}{|l|l|l|l|l|l|l|l|l|l|}
\hline 5 & 0.501 & 0.412 & 0.212 & 0.619 & 20 & 0.501 & 0.331 & 0.212 & 0.619 \\
\hline 6 & 0.397 & 0.324 & 0.212 & 0.619 & 21 & 0.574 & 0.358 & 0.212 & 0.619 \\
\hline 7 & 0.445 & 0.438 & 0.212 & 0.619 & 22 & 0.342 & 0.302 & 0.203 & 0.628 \\
\hline 8 & 0.258 & 0.296 & 0.212 & 0.619 & 23 & 0.412 & 0.336 & 0.165 & 0.667 \\
\hline 9 & 0.604 & 0.273 & 0.212 & 0.619 & 24 & 0.426 & 0.367 & 0.212 & 0.619 \\
\hline 10 & 0.412 & 0.410 & 0.212 & 0.619 & 25 & 0.461 & 0.312 & 0.212 & 0.619 \\
\hline 11 & 0.519 & 0.389 & 0.212 & 0.619 & 26 & 0.352 & 0.323 & 0.212 & 0.619 \\
\hline 12 & 0.422 & 0.351 & 0.212 & 0.619 & 27 & 0.441 & 0.342 & 0.212 & 0.619 \\
\hline 13 & 0.303 & 0.342 & 0.212 & 0.619 & 28 & 0.231 & 0.197 & 0.165 & 0.667 \\
\hline 14 & 0.691 & 0.297 & 0.212 & 0.619 & 29 & 0.319 & 0.325 & 0.212 & 0.619 \\
\hline 15 & 0.457 & 0.335 & 0.212 & 0.619 & 30 & 0.501 & 0.302 & 0.212 & 0.619 \\
\hline & & & & & & & MSD $=0.33$ & & \\
\hline
\end{tabular}

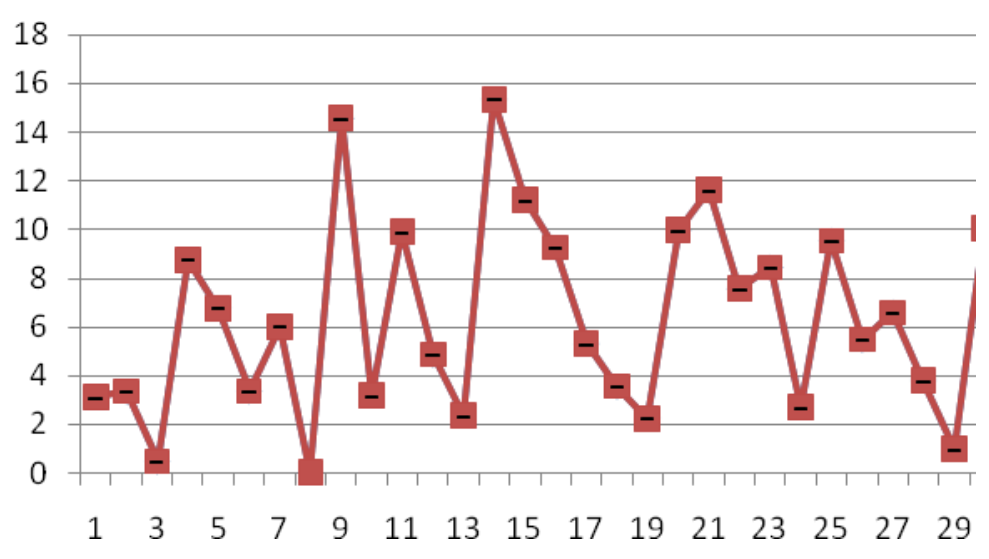

Fig4. Fuzzy probabilistic control chart (fuzzy mode)

Table 7 . Results of applying fuzzy probabilistic approach (fuzzy median for set 1)

\begin{tabular}{|c|c|c|c|c|c|c|c|c|c|}
\hline Samples & $\mathrm{Mj}$ & $\mathrm{SDj}$ & $\mathrm{LCL}$ & $\mathrm{UCL}$ & Samples & $\mathrm{Mj}$ & $\mathrm{SDj}$ & $\mathrm{LCL}$ & UCL \\
\hline 1 & 0.431 & 0.273 & 0.288 & 0.608 & 16 & 0.473 & 0.252 & 0.273 & 0.623 \\
\hline 2 & 0.419 & 0.312 & 0.288 & 0.608 & 17 & 0.413 & 0.236 & 0.288 & 0.608 \\
\hline 3 & 0.333 & 0.236 & 0.288 & 0.608 & 18 & 0.438 & 0.245 & 0.288 & 0.608 \\
\hline 4 & 0.512 & 0.245 & 0.288 & 0.608 & 19 & 0.373 & 0.231 & 0.288 & 0.608 \\
\hline 5 & 0.503 & 0.327 & 0.288 & 0.608 & 20 & 0.509 & 0.267 & 0.288 & 0.608 \\
\hline 6 & 0.448 & 0.281 & 0.288 & 0.608 & 21 & 0.553 & 0.290 & 0.288 & 0.608 \\
\hline 7 & 0.501 & 0.347 & 0.288 & 0.608 & 22 & 0.421 & 0.223 & 0.281 & 0.615 \\
\hline 8 & 0.318 & 0.224 & 0.288 & 0.608 & 23 & 0.437 & 0.286 & 0.251 & 0.645 \\
\hline 9 & 0.579 & 0.218 & 0.288 & 0.608 & 24 & 0.452 & 0.277 & 0.288 & 0.608 \\
\hline 10 & 0.421 & 0.301 & 0.288 & 0.608 & 25 & 0.487 & 0.266 & 0.288 & 0.608 \\
\hline 11 & 0.537 & 0.310 & 0.288 & 0.608 & 26 & 0.419 & 0.252 & 0.288 & 0.608 \\
\hline 12 & 0.418 & 0.274 & 0.288 & 0.608 & 27 & 0.434 & 0.250 & 0.288 & 0.608 \\
\hline 13 & 0.408 & 0.253 & 0.288 & 0.608 & 28 & 0.325 & 0.168 & 0.251 & 0.645 \\
\hline 14 & 0.652 & 0.242 & 0.288 & 0.608 & 29 & 0.379 & 0.258 & 0.288 & 0.608 \\
\hline 15 & 0.479 & 0.263 & 0.288 & 0.608 & 30 & 0.499 & 0.231 & 0.288 & 0.608 \\
\hline
\end{tabular}


Table 8 . Results of applying fuzzy probabilistic approach (fuzzy median for set 2)

\begin{tabular}{|c|c|c|c|c|c|c|c|c|c|}
\hline Samples & $\mathrm{Mj}$ & $\mathrm{SDj}$ & $\mathrm{LCL}$ & $\mathrm{UCL}$ & Samples & $\mathrm{Mj}$ & SDj & LCL & UCL \\
\hline 1 & 0.362 & 0.235 & 0.232 & 0.510 & 16 & 0.412 & 0.203 & 0.219 & 0.523 \\
\hline 2 & 0.331 & 0.270 & 0.232 & 0.510 & 17 & 0.378 & 0.210 & 0.232 & 0.510 \\
\hline 3 & 0.264 & 0.227 & 0.232 & 0.510 & 18 & 0.350 & 0.214 & 0.232 & 0.510 \\
\hline 4 & 0.439 & 0.198 & 0.232 & 0.510 & 19 & 0.301 & 0.215 & 0.232 & 0.510 \\
\hline 5 & 0.399 & 0.265 & 0.232 & 0.510 & 20 & 0.451 & 0.216 & 0.232 & 0.510 \\
\hline 6 & 0.383 & 0.246 & 0.232 & 0.510 & 21 & 0.460 & 0.241 & 0.232 & 0.510 \\
\hline 7 & 0.415 & 0.288 & 0.232 & 0.510 & 22 & 0.337 & 0.212 & 0.226 & 0.516 \\
\hline 8 & 0.267 & 0.218 & 0.232 & 0.510 & 23 & 0.353 & 0.233 & 0.200 & 0.542 \\
\hline 9 & 0.493 & 0.162 & 0.232 & 0.510 & 24 & 0.365 & 0.245 & 0.232 & 0.510 \\
\hline 10 & 0.352 & 0.273 & 0.232 & 0.510 & 25 & 0.409 & 0.213 & 0.232 & 0.510 \\
\hline 11 & 0.339 & 0.248 & 0.232 & 0.510 & 26 & 0.327 & 0.213 & 0.232 & 0.510 \\
\hline 12 & 0.435 & 0.244 & 0.232 & 0.510 & 27 & 0.384 & 0.221 & 0.232 & 0.510 \\
\hline 13 & 0.376 & 0.231 & 0.232 & 0.510 & 28 & 0.275 & 0.154 & 0.200 & 0.542 \\
\hline 14 & 0.538 & 0.186 & 0.232 & 0.510 & 29 & 0.302 & 0.224 & 0.232 & 0.510 \\
\hline 15 & 0.384 & 0.216 & 0.232 & 0.510 & 30 & 0.432 & 0.189 & 0.232 & 0.510 \\
\hline
\end{tabular}

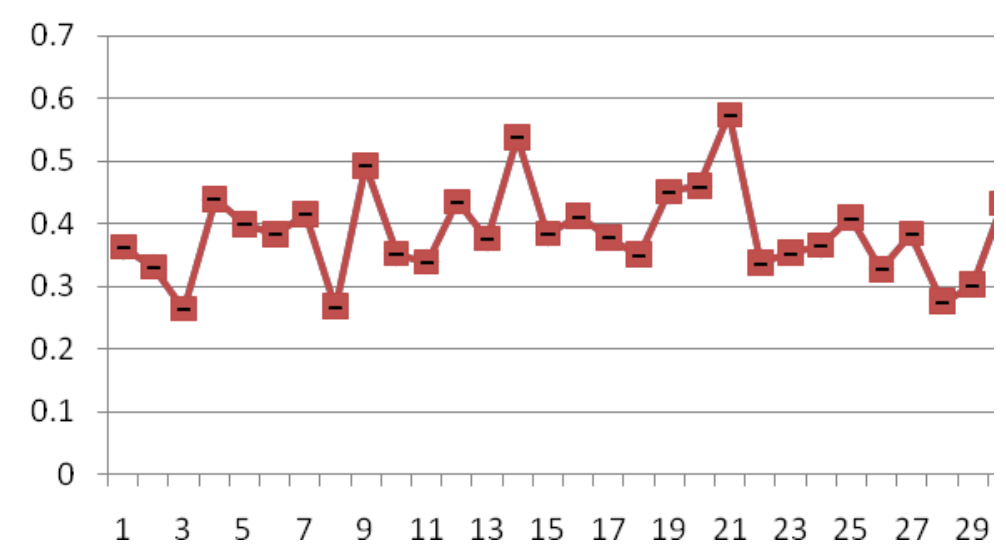

Fig5. Fuzzy probabilistic quality control chart (fuzzy median, set 2)

\section{Membership Approach}

The membership functions of the fuzzy subsets for the mean of the samples are determined. By using the first sample to illustrate the calculation, the fuzzy subset MF1 associated with the sample mean can be represented by $(\mathrm{a} 1, \mathrm{~b} 1, \mathrm{c} 1)$ where,

$\mathrm{a} 1=[(0 \times 6)+(0 \times 9)+(0.25 \times 4)+(0.50 \times 5)] / 24=0.146 \ldots \mathrm{left}$

$\mathrm{b} 2=[(0 \times 6)+(0.25 \times 9)+(0.5 \times 4)+(1 \times 5)] / 24=0.385 \ldots$ mode

$\mathrm{c} 2=[(0.5 \times 6)+(0.75 \times 9)+(1 \times 4)+(1 \times 5)] / 24=0.781 \ldots$ right

The resulting left ends, modes and right ends of these 30 samples are given in Table 9 . The fuzzy subsets associated with the linguistic terms are all triangular fuzzy subsets. Then the corresponding representative value is calculated. The result obtained is shown in last column of Table 9. Fuzzy mode is used as a transformation method. The mean deviation is calculated according to Eq. 8. Since the fuzzy 
subset GMF can be represented by a triplet $(0.162,0.416,0.793)$, and the mean deviation is calculated as 0.315 . The centerline is obtained by transforming GMF into a representative value. The resulting value is 0.416. Then control limits are calculated with Eq. 9. While calculating these limits, the value of $\mathrm{k}$ which is the number of mean deviations that the control limits will be located away from centerline is taken as 0.7 . The representative value to be plotted on the chart, center line, upper and lower control limits are shown in Table 10. Control chart following the membership approach according to fuzzy mode transformation method is constructed and shown in Fig. 4. As can be from Fig. 4, the samples 3, 8, 14 are out of the control. The sample 14 is out of control at both fuzzy probabilistic and membership control chart. And the samples 3 and 8 which are out of control in fuzzy membership control chart are very close the upper control limit at fuzzy probabilistic control charts. With the comparison between fuzzy probabilistic chart and the fuzzy membership chart constructed for Set 1 by using fuzzy mode as a transformation method in other words comparison of those two control charts it can be seen that membership approach always produces narrower band between control limits than the probabilistic approach. Fuzzy probabilistic and membership control charts produce approximately same result for yarn quality.

Table 9. Parameters of the fuzzy subset with each sample (for set 1)

\begin{tabular}{|c|c|c|c|c|c|c|c|c|c|}
\hline Samples & $\begin{array}{c}\text { Left } \\
\text { end }\end{array}$ & Mode & Right end & Fuzzy mode & Samples & Left end & Mode & Right end & $\begin{array}{c}\text { Fuzzy } \\
\text { Mod }\end{array}$ \\
\hline 1 & 0.143 & 0.389 & 0.779 & 0.385 & 16 & 0.163 & 0.471 & 0.835 & 0.475 \\
\hline 2 & 0.159 & 0.379 & 0.763 & 0.374 & 17 & 0.171 & 0.432 & 0.815 & 0.427 \\
\hline 3 & 0.097 & 0.265 & 0.701 & 0.242 & 18 & 0.145 & 0.364 & 0.803 & 0.375 \\
\hline 4 & 0.217 & 0.448 & 0.877 & 0.456 & 19 & 0.098 & 0.302 & 0.744 & 0.302 \\
\hline 5 & 0.199 & 0.493 & 0.810 & 0.498 & 20 & 0.178 & 0.489 & 0.853 & 0.490 \\
\hline 6 & 0.182 & 0.404 & 0.810 & 0.402 & 21 & 0.251 & 0.571 & 0.841 & 0.563 \\
\hline 7 & 0.222 & 0.463 & 0.798 & 0.481 & 22 & 0.101 & 0.360 & 0.784 & 0.352 \\
\hline 8 & 0.080 & 0.247 & 0.700 & 0.242 & 23 & 0.137 & 0.401 & 0.751 & 0.391 \\
\hline 9 & 0.243 & 0.596 & 0.871 & 0.606 & 24 & 0.159 & 0.386 & 0.803 & 0.396 \\
\hline 10 & 0.177 & 0.406 & 0.775 & 0.383 & 25 & 0.173 & 0.487 & 0.813 & 0.458 \\
\hline 11 & 0.229 & 0.501 & 0.837 & 0.521 & 26 & 0.105 & 0.351 & 0.776 & 0.344 \\
\hline 12 & 0.147 & 0.386 & 0.751 & 0.407 & 27 & 0.165 & 0.436 & 0.802 & 0.427 \\
\hline 13 & 0.118 & 0.333 & 0.749 & 0.333 & 28 & 0.071 & 0.240 & 0.749 & 0.250 \\
\hline 14 & 0.319 & 0.698 & 0.921 & 0.690 & 29 & 0.112 & 0.298 & 0.730 & 0.302 \\
\hline 15 & 0.160 & 0.438 & 0.797 & 0.453 & 30 & 0.194 & 0.52 & 0.830 & 0.490 \\
\hline & & & & & Average & 0.171 & 0.426 & 0.793 & 0.416 \\
\hline
\end{tabular}

Table 10 . Results of applying fuzzy membership approach (fuzzy mode)

\begin{tabular}{|c|c|c|c|c|c|c|c|c|c|}
\hline Samples & Repr. value & CL & UCL & LCL & Samples & Repr. value & CL & UCL & LCL \\
\hline 1 & 0.374 & 0.416 & 0.259 & 0.574 & 16 & 0.483 & 0.416 & 0.259 & $\begin{array}{c}0.57 \\
4\end{array}$ \\
\hline 2 & 0.365 & 0.416 & 0.259 & 0.574 & 17 & 0.432 & 0.416 & 0.259 & $\begin{array}{c}0.57 \\
4\end{array}$ \\
\hline 3 & 0.239 & 0.416 & 0.259 & 0.574 & 18 & 0.381 & 0.416 & 0.259 & $\begin{array}{c}0.57 \\
4\end{array}$ \\
\hline 4 & 0.452 & 0.416 & 0.259 & 0.574 & 19 & 0.302 & 0.416 & 0.259 & $\begin{array}{c}0.57 \\
4\end{array}$ \\
\hline
\end{tabular}


Hamid Reza Feili, Pooyan Fekraty / TJMCS Vol .1 No.4 (2010) 257-272

\begin{tabular}{|c|c|c|c|c|c|c|c|c|c|}
\hline 5 & 0.486 & 0.416 & 0.259 & 0.574 & 20 & 0.486 & 0.416 & 0.259 & $\begin{array}{c}0.57 \\
4\end{array}$ \\
\hline 6 & 0.403 & 0.416 & 0.259 & 0.574 & 21 & 0.573 & 0.416 & 0.259 & $\begin{array}{c}0.57 \\
4\end{array}$ \\
\hline 7 & 0.480 & 0.416 & 0.259 & 0.574 & 22 & 0.352 & 0.416 & 0.259 & $\begin{array}{c}0.57 \\
4\end{array}$ \\
\hline 8 & 0.251 & 0.416 & 0.259 & 0.574 & 23 & 0.402 & 0.416 & 0.259 & $\begin{array}{c}0.57 \\
4\end{array}$ \\
\hline 9 & 0.579 & 0.416 & 0.259 & 0.574 & 24 & 0.396 & 0.416 & 0.259 & $\begin{array}{c}0.57 \\
4\end{array}$ \\
\hline 10 & 0.401 & 0.416 & 0.259 & 0.574 & 25 & 0.464 & 0.416 & 0.259 & $\begin{array}{c}0.57 \\
4\end{array}$ \\
\hline 11 & 0.536 & 0.416 & 0.259 & 0.574 & 26 & 0.353 & 0.416 & 0.259 & $\begin{array}{c}0.57 \\
4\end{array}$ \\
\hline 12 & 0.412 & 0.416 & 0.259 & 0.574 & 27 & 0.432 & 0.416 & 0.259 & $\begin{array}{c}0.57 \\
4\end{array}$ \\
\hline 13 & 0.333 & 0.416 & 0.259 & 0.574 & 28 & 0.256 & 0.416 & 0.259 & $\begin{array}{c}0.57 \\
4\end{array}$ \\
\hline 14 & 0.688 & 0.416 & 0.259 & 0.574 & 29 & 0.307 & 0.416 & 0.259 & $\begin{array}{c}0.57 \\
4\end{array}$ \\
\hline 15 & 0.448 & 0.416 & 0.259 & 0.574 & 30 & 0.490 & 0.416 & 0.259 & $\begin{array}{c}0.57 \\
4\end{array}$ \\
\hline
\end{tabular}

\section{Conclusion}

Control charts have an efficient usage field to keep the process under control. Control charts are accepted as graphical analysis method which determines the products whether to remain in the acceptable limits or not and as a graphical analysis method which gives a signal in the case of product to be out of these limits. In this paper control chart and fuzzy logic are tried to combine. Because the most important difference of fuzzy logic from the other logic systems is that it allows the using linguistic variables. Linguistic variables provide the concepts which cannot be expressed clearly to be qualified approximately. In this study to supplement the binary classification, several intermediate levels which describe product quality are used. These intermediate levels are expressed in the form of linguistic terms with the help of fuzzy logic. Fuzzy probabilistic and membership control charts which were proposed by Wang and Raz are constructed. At the same time generalized $\mathrm{p}$ chart which depends on probability theory is constructed. With comparison of probability and fuzzy theory, fuzzy theory performs better than probability theory in monitoring the multinomial process for the textile industry. Construction of fuzzy control chart has some advantages and disadvantages. The major contribution of fuzzy set theory is its capability of representing vague data. With the help of the fuzzy set theory, flexibility of the system is improved. In general, big variations in the fuzzy system's output can also be achieved by directly manipulating the membership functions and overlap properties. Contrarily to other intelligent techniques such as neural networks, the lengthy training phases are not necessary for fuzzy systems and their design can be interpreted as being more semantic than the design of other intelligent techniques. The main difficulty of constructing fuzzy control chart is selecting suitable membership function of linguistic variables. The assignment of membership function to each linguistic variable is not easy for process and quality engineers. The shape of membership function should be based on system behavior and user's preferences. And also increasing and decreasing number of linguistic variables affect the performance of fuzzy control chart. In the result of this study, it's possible to say that building fuzzy control charts have more flexible and more appropriate mathematical description frame than control chart approach and give more meaning results than traditional quality chart. 


\section{References}

[1] Anderson, D. R., Sweeney, D. J., \& Williams, T. A. (1996). Statistics for business and economics. St. Paul: West Publishing Company.

[2] Bayrak, M. Y., Çelebi, N., \& Taskın, H. (2007). A fuzzy approach method for supplier selection. Production Planning and Control, 18(1), 54-63.

[3] Berenson, M. L., \& Levine, D. M. (1999). Basic business statistics. New Jersey: Prentice Hall.

[4] Bojadziev, G., \& Bojadziev, M. (1991). Fuzzy sets, fuzzy logic, applications. London: World Scientific.

[5] Bradshaw, C. W. (1983). A fuzzy set theoretic interpretation of economic control limits. European Journal of Operational Research,13, 403-408.

[6] Cheng, C. (2005). Fuzzy process control: Construction of control charts with fuzzy numbers. Fuzzy Sets and Systems, 154(2), 287-303.

[7] Ertu grul, 'I. (2004). Toplam kalite kontrol ve teknikleri. Bursa: Ekin Kitabevi.

[8] Franceschini, F., \& Romano, D. (1999). Control chart for linguistic variables: A method based on the use of linguistic quantifiers. International Journal of Production Research, 37(16), 37913801.

[9] Franceschini, F., Galetto, M., \& Varetto, M. (2005). Ordered samples control charts for ordinal variables. Quality and Reliability Engineering International, 21, 177-195.

[10] Guiffrida, A. L., \& Nagi R. (1998). Fuzzy set theory application in production management research: A literature survey. Journal of Intelligent Manufacturing. 9(1), 39-56.

[11] Gülbay, M., Kahraman, C., \& Ruan, D. (2004). $\alpha$-cut fuzzy control charts for linguistic data. International Journal of Intelligent Systems, 19, 1173-1195.

[12] Gülbay, M., \& Kahraman, C. (2007). An alternative approach to fuzzy control charts: Direct fuzzy approach. Information Sciences, 177, 1463-1480.

[13] Kahraman, C., Tolga, E., \& Ulukan, Z. (1995). Using triangular fuzzy numbers in the tests of control charts for unnatural patterns. In Proceedings of INRIA/IEEE conference on emerging technologies and factory automation (Vol. 3, pp. 291-298). October 10-13, Paris, France.

[14] Kanagawa, A., Tamaki, F., \& Ohta, H. (1993). Control charts for process average and variability based on linguistic data. International Journal of Production Research, 31(4), 913-922. [15] Kandel, A. (1986). Fuzzy mathematical techniques with applications. Boston: Addison-Wesley Publishing Company.

[16] Korvin, A., \& Shipley, M. F. (2001). Sample size: Achieving quality and reducing financial loss. International Journal of Quality \& Reliability Management, 18(7), 678-691.

[17] Krajewski, L. J., \& Ritzman, L. P. (1998). Operations management/ strategy and analysis. Glenview: Addison-Wesley Publishing Company.

[18] Martinich, J. S. (1997). Production and operations management: An applied modern approach. USA: Wiley.

[19] Montgomery, D. C. (1991). Introduction to statistical quality control. New York: Wiley. [20] Raz,T.,\&Wang, J. H. (1990). Probabilistic andmembership approaches in the construction of control charts for linguistic data. Production Planning \& Control, 1, 147-157.

[21] Rowlands, H., \&Wang, L. R. (2000). An approach of fuzzy logic evaluation and control in SPC. Quality \& Reliability Engineering International, 16, 91-98.

[22] Stevenson,W. (1993). Production/operationmanagement.Homewood: Irwin. 
[23] Taleb, H., \& Limam, M. (2002). On fuzzy and probabilistic control charts. International Journal of Production Research, 40(12), 2849-2863.

[24] Taleb, H., \& Limam, M. (2005). Fuzzy multinominal control charts. In AI*IA 2005: 9th Congress of the Italian Association for Artificial Intelligence (Vol. 3673, pp. 553-563). September 21-23, Milan, Italy.

[25] Wang, C. R., \& Chen, C. H. (1995). Economic statistical np control chart designs based on fuzzy optimization. International Journal of Quality \& Reliability Management, 12(1), 82-92.

[26] Wang, J. H., \& Raz, T. (1990). On the construction of control charts using linguistic variables. International Journal of Production Research, 28(3), 477-487.

[27] Yen, J., \& Langari, R. (1999). Fuzzy logic, intelligence, control and information. New Jersey: Prentice Hall.

[28] Zadeh, L. A., \& Kacprzyk, J. (1992). Fuzzy logic for the management of uncertainty. New York: Wiley 